\title{
VII
}

\section{CAPITALISMO DEPENDENTE, (CONTRA)REVOLUÇÃO BURGUESA E UNIVERSIDADE PÚBLICA*}

Alexandre Rola

\section{INTRODUÇÃO}

O presente capítulo é fruto dos debates realizados no Grupo de Estudos e Pesquisas em Educação e Serviço Social da Universidade Federal Fluminense (GEPESS-UFF) e da pesquisa de dissertação em curso no Programa de Pós-Graduação em Direito da Universidade Federal do Rio de Janeiro (PPGDUFRJ) com título "Capitalismo dependente e Autonomia Universitária: Um diálogo com Florestan Fernandes sobre a construção do artigo 207 da Constituição da República Federativa do Brasil".

Buscaremos apresentar um conjunto de reflexões sobre o desenvolvimento do capitalismo no Brasil, identificado por Florestan Fernandes ao longo de sua obra, prestando especial atenção ao padrão de dominação externo, a forma particular de revolução burguesa e como estas se relacionam com a configuração da universidade pública brasileira.

Este capítulo, que possuí forte conexão com os capítulos 2 e 4 do presente livro, será dividido em três partes. Na primeira parte iremos, com base em Fernandes (2009), analisar os padrões de dominação externa que ocorrerem na América Latina desde o "descobrimento" até os dias atuais, em combinação com a forma particular de revolução (uma verdadeira contrarrevolução) burguesa específica do Brasil e como estes elementos estruturantes do capitalismo dependente afetaram a constituição e as mudanças estruturais da universidade no país.

$\mathrm{Na}$ segunda parte, analisaremos a atual fase da inserção capitalista dependente do Brasil na economia mundial, que se inicia no período da "transição democrática" até os dias de hoje, nos debruçando sobre a postura dos diferentes governos neste período, examinando as alterações na educação superior brasileira. Tentaremos demonstrar que, pós-2016, no Brasil, a contrarrevolução 
burguesa passa a assumir sua forma "a quente" semelhante àquela do período da ditadura civil-militar-empresarial.

Por fim, apresentaremos os principais desafios para a classe trabalhadora no sentido de enfrentar o processo de contrarrevolução burguesa em curso no país, especialmente pela defesa intransigente da universidade pública como lócus de produção de conhecimento científico.

\section{PADRÃO DE DOMINAÇÃO EXTERNO, REVOLUÇÃO BURGUESA E UNIVERSIDADE PÚBLICA}

Como vimos nos capítulos anteriores do presente livro, o padrão de sociabilidade brasileiro tem entre seus elementos estruturantes: I) o padrão dual de expropriação e espoliação do excedente de capital; II) o padrão compósito de dominação burguesa que se expressa de forma autocrática; e III) uma forma específica de políticas educacionais. Estes elementos estruturantes são responsáveis pela forma como se constituí a universidade pública no Brasil e como esta instituição é utilizada para produzir e reproduzir estes elementos estruturantes.

Para entendermos como a universidade pública é constituída no Brasil e a relação dos governos com esta instituição, em determinados períodos sóciohistóricos da formação brasileira, é preciso reconhecer que ela, como instituição de Estado, é organizadora do poder (e prestígio) dentro da nossa formação social e de uma forma de produção econômica específica (FERNANDES, 2011), assim como compreender o potencial contestador do meio acadêmico, tanto "dentro da ordem" como "contra a ordem" (FERNANDES, 2020a).

Porém, é necessário examinarmos mais a fundo como estes elementos estruturantes se deram como resultado das transformações societárias no Brasil e da "revolução burguesa"1 possível no capitalismo dependente, visto que o capitalismo dependente tem particularidades que necessitam ser mediadas e apreendidas. Isso porque, "[...] remontando às suas determinações ontológicas (universalidade e particularidade) o singular pode ser apreendido exatamente em seus nexos internos e externos" (MAZZEO, 2015, p. 25).

É importante realizar esta mediação para apreendermos, em sua materialidade, os caminhos da formação social brasileira, a formação de sua burguesia

\footnotetext{
${ }^{1}$ Como demonstraremos a seguir, a forma como a revolução burguesa se dá nos países de capitalismo dependente assume uma forma verdadeiramente contrarrevolucionária, com características próprias que a distinguem das revoluções típicas e atípicas dos países de capitalismo central (FERNANDES, 2020b).
} 
e como esta afeta a universidade pública, garantindo assim, o rigor do método marxista, não vulgarizando-o ${ }^{2}$.

Foi com esta categoria central em mente, que Fernandes (2009, 2020b) traçou um paralelo das formas de dominação externa que as sociedades da América Latina vivenciaram durante suas formações e as transformações da sociedade brasileira, identificando quatro momentos desta dominação e afirmando que o Brasil é um dos países, dentre os países latino-americanos, que vivenciou estas quatro formas. E é com base nesta análise que trataremos as particularidades da burguesia nacional e sua concepção de educação e de universidade.

A primeira fase da dominação externa se deu através do "antigo sistema colonial" que possuía um duplo fundamento: legal e político. Ao preservar e ampliar os interesses das Coroas e dos colonizadores, o que se viu foi uma transplantação dos padrões de estrutura social, com as devidas adaptações (por exemplo, trabalho escravo), das metrópoles para as colônias. Esta fusão dos interesses das Coroas e dos colonizadores, produziu uma verdadeira sociedade colonial, onde apenas os colonizadores participariam das estruturas de poder e seriam capazes de transmitir, por meio da linhagem "europeia", sua posição social (FERNANDES, 2009).

Esta fase é marcante, pois a dominação externa era exercida diretamente sob a sociedade brasileira, sendo os colonizadores meros vassalos organizadores e executores do interesse das Coroas, o que permitiu a formação de identidade entre interesses dos colonizadores e das Coroas e vice-versa (FERNANDES, 2009).

Neste primeiro período, a concepção de educação que se tinha era de que cabia aos jesuítas a catequização dos povos originários, sem o interesse da Coroa e nem dos Colonizadores em constituir um sistema educacional nacional. Esta organização educacional de cunho religioso em solo colonial manteve o lastro dependente, uma vez que os filhos dos colonizadores recorriam as instituições de educação superior da Coroa portuguesa e demais países europeus (MINTO, 2014).

Com a crise deste sistema a partir da incapacidade econômica e política de Portugal em sustentar as atividades mercantis do sistema colonial e com a expansão das economias dos países que vivenciaram o período de acumulação

\footnotetext{
${ }^{2}$ Como nos aponta Netto (2018), a teoria marxista deve muito a seus predecessores, como Hegel que apresentou a noção do círculo constituído de círculos, ou seja, que a realidade é um complexo formado por complexos. Foi a ausência dessa categoria, de entender a particularidade como um campo de mediações entre a universalidade e a singularidade que permitiu a vulgarização da teoria marxista.
} 
capitalista e suas revoluções burguesas, em especial Inglaterra, dá-se início a um novo período.

Esta segunda fase, caracterizou-se pela dominação, mais indireta (em contraponto à dominação legal e política do período anterior) das, agora, antigas colônias através da monopolização do mercado interno, que estava em crescimento e já contava com as estruturas necessárias para a exportação de insumos para as sociedades centrais do sistema capitalista. Fernandes (2009) vai caracterizar este período de neocolonialismo.

Aqui podemos falar nas oligarquias agrárias locais, senhores rurais e seus parceiros comerciantes locais como estamentos dominantes no período neocolonial. Estas oligarquias, senhores rurais e comerciantes detinham o controle dos meios de produção e comércio desta produção, mantendo as estruturas do "antigo regime", ou seja, a produção centrada nos latifúndios e regime de trabalho escravagista e semiescravagista para a exportação. Neste período começam a surgir as "[...] escolas profissionalizantes das áreas tradicionais (Direito, Medicina e Engenharia, principalmente)" (MINTO, 2014, p. 137), que se consolidaram como locais de preparação da elite brasileira - instituições de transferência de prestígio - preparando os filhos da classe dominante para as novas fases do desenvolvimento do capitalismo no Brasil. Cabe destacar que estas escolas vão se constituir como as protoformas das Escolas Superiores no Brasil.

Já a terceira fase de dominação externa, reflexo da revolução industrial na Europa (que foi financiada através da exploração do sistema colonial), provocou novas formas de articulação das economias periféricas e economias centrais. Estas novas formas de articulação estiveram ligadas, tanto ao surgimento da fase anterior dos mercados nas ex-colônias, como à expansão das influências econômicas, políticas, culturais e sociais dos países centrais sobre os países periféricos. Assim, esta reconfiguração originou o imperialismo das sociedades centrais e o capitalismo dependente nas sociedades periféricas durante as últimas décadas do século XIX (FERNANDES, 2009).

A partir deste reordenamento, o que se viu foi um controle extremamente complexo, fazendo com que a lógica exportação-importação começasse a se modificar para transformar as próprias economias dependentes em mercadorias através da expansão bancária, proteção dos interesses rurais, integração do comércio interno, dentre outros (FERNANDES, 2009).

Foi neste momento que um dos aspectos negativos desta lógica dependente começou a se aprofundar. Com a expansão do mercado, a "moderniza- 
ção da sociedade" se torna um fato inconteste, porém, dentro da lógica capitalista, para que esta modernização acontecesse era necessário que o traço colonial antigo (pré-capitalista e extra capitalista) se mantivesse para abastecer o setor que se modernizava e industrializava-se. Este fenômeno deu origem ao desenvolvimento desigual da sociedade brasileira, onde estruturas pré-capitalistas e extra capitalistas se conciliam a estruturas de produção capitalista modernas ${ }^{3}$. Esta forma de desenvolvimento desigual e combinado (TROTSKY, 2007) e o padrão articulado de dominação burguesa (interna e externa), formam os elementos estruturantes do método de produção capitalista dependente.

Esta modernização somente foi possível com a ascensão da fase imperialista total (FERNANDES, 2009), onde em razão do capitalismo assumir sua fase monopolista, a relação de dependência passa a ser reforçada através de mecanismos financeiros e da associação entre sócios estrangeiros e locais, permitindo a dominação externa a partir de dentro e em todos os níveis sociais (incluído a educação). Este padrão de hegemonia que realiza a integração mais completa dos interesses internos e externos foi denominado por Fernandes (2008; 2009; 2020b) de padrão compósito de hegemonia burguesa, produtor e reprodutor da autocracia burguesa no Brasil (FERNANDES, 2020b).

É nesta fase que se dá o começo da "revolução burguesa" no Brasil. Porém, esta revolução (uma verdadeira contrarrevolução), assumiu características próprias, distinguindo-se das revoluções burguesas típicas e atípicas do capitalismo central, como visto no capítulo dois deste livro. Isto porque a burguesia local não possuía o espírito anti-imperialista típico das outras formas de burguesias dos países centrais, não podendo ou desejando romper com o padrão compósito de dominação, por este ser um dos seus requisitos de dominação local e de prestígio como agente produtor e reprodutor do capitalismo no Brasil.

Como Fernandes (2020b) extensamente observa e detalha, a burguesia brasileira, formada a partir da articulação entre a burguesia urbana do período anterior, a jovem burguesia industrial que passa a surgir neste período da formação do capitalismo dependente e absorção sem destruição dos estamentos dominantes do antigo regime, constituem uma burguesia com interesses confli-

\footnotetext{
${ }^{3}$ Oliveira (2013) tece críticas à lógica da existência de "dois brasis" um moderno e um arcaico. Em seu estudo, o autor identifica que há no Brasil em verdade a convivência interligada (desigual e combinada, para utilizar um termo de Florestan) dos dois modelos de exploração capitalista. $\mathrm{O}$ modelo moderno, industrial e financeiro e o modelo arcaico cujas raízes se encontram na lógica da acumulação pré-capitalista (colonialismo). Fernandes (2020b) fala em um "colonialismo interno" - em uma arcaização do moderno e uma modernização do arcaico (2008).
} 
tantes, porém, com um elemento estruturante da sua solidariedade de classe: a necessidade de manter a acumulação de renda, poder e prestígio. Estes sãos os interesses que unem as frações da classe burguesa formada neste período, forjando um tipo particular de solidariedade de classes, fornecendo as primeiras pistas para caracterização da revolução burguesa brasileira como uma contrarrevolução preventiva.

Para tanto, o padrão compósito de hegemonia burguesa e a dupla expropriação e espoliação do excedente de capital não podiam e não podem ser afetados, fazendo com que a classe burguesa não possa conviver com tensões, mesmo aquelas "dentro da ordem". Para esta burguesia, ser "democrática" ou "nacionalista" não pode passar de meros símbolos de uma moral, esvaziando seu significado político ou prático (FERNANDES, 2020b).

É em razão desta particular solidariedade de classes que o Estado se torna extremamente importante para a classe burguesa, pois é através do controle deste que a burguesia local pode realizar seus objetivos de acumulação de renda, de manutenção de seu prestígio frente as burguesias externas e exercer, portanto, o seu poder como classe dominante. É através do controle do Estado que a burguesia local consegue realizar sua função interna de preservação da ordem e fortalecimento do capitalismo, assim como manter seu prestígio como um dos "pilares da ordem capitalista", "da sociedade ocidental" e "da moral cristã" (FERNANDES, 2020b).

Para conduzir internamente o padrão compósito de hegemonia burguesa, a burguesia não pode perder o controle do Estado, pois caso assim fosse poria em risco o próprio capitalismo dependente. Não podendo perder o controle do Estado, pois tudo que faz a burguesia ter solidariedade de classes depende deste poder, a burguesia assume a contrarrevolução preventiva ${ }^{4}$ como forma de sua "revolução burguesa".

Esta contrarrevolução que pode ter momentos "a quente" e "frio", sendo o primeiro momento "[...] associada ao regime burguês-militar e ao Estado autocrático burguês" (LIMA, 2019, p. 97) e o segundo

[...] com a "situação sob controle", a defesa a quente da ordem pode ser feita sem que os 'organismos de segurança' necessitem do suporte tático de um clima de guerra civil, embora este se mantenha, através da repressão policial-militar e da "compressão política" (FERNANDES, 2020b, p. 442).

\footnotetext{
${ }^{4}$ Para uma maior explicação de contrarrevolução na teoria marxista clássica e na visão de Flores$\tan$ Fernandes, ver capítulo 2 deste livro.
} 
É neste momento de formação de uma classe burguesa no Brasil que há um novo movimento de conciliação entre as frações das classes dominantes, agora não mais Coroa-Colonizador, mas sim ruralistas, frações das pequenas e médias burguesas e da burguesia industrial com suas burguesias parceiras nos países centrais e é neste contexto que as primeiras universidades brasileiras começam a surgir, para preparação de novos quadros dirigentes e de seu status, o Brasil necessitava também expandir os cursos para acolher a burguesia industrial que se formava (MINTO, 2014).

Conforme Fernandes (2009) e Minto (2014), as novas demandas da configuração das classes determinaram o surgimento das primeiras universidades, agora não mais como extensão dos interesses da Coroa, mas como constitutivas da organização do Brasil na divisão internacional do trabalho.

A quarta fase, intitulada "neo-capitalismo", no marco temporal histórico iniciar-se-á no período da ditadura civil-militar-empresarial, e adentrará o período pós redemocratização. De acordo com Fernandes (2009), o "neo-capitalismo" é caracterizado pela integração entre mercado interno e externo na fase madura do capitalismo, assim como a conciliação entre os interesses da burguesia local e internacional, trazendo para o âmbito da educação superior novos reordenamentos. Nesta fase, o interesse da burguesia era sua ampliação para, não mais apenas formar seus filhos para assumir seu lugar, mas também formar uma classe trabalhadora qualificada para o mercado (sem formação crítica) a fim de atender às demandas da industrialização nacional.

Foi neste momento de dominação externa, que se dá a ditadura civilmilitar-empresarial, estabelecida no Brasil entre 1964 e 1985, trazendo graves repercussões para o ensino superior e servindo também como laboratório neoliberal (como no caso da ditadura de Pinochet), sendo visível esse aspecto na Reforma Universitária de $1968^{5}$.

É neste momento que a contrarrevolução burguesa assume sua forma "a quente" frente a um novo temor da classe burguesa. Não o temor de que estivesse o Brasil em uma fase pré-revolucionária, mas que talvez pudesse levar ao surgimento de condições materiais para uma fase pré-revolucionária. Em razão de governos de "base populista" e de uma possível automação do Estado em razão do surgimento de uma "alta burocracia nacionalista" e do "tamanho do próprio Estado", surge o medo de que estes governos pudessem representar a "perda do controle do Estado pela burguesia" (FERNANDES, 2020b).

\footnotetext{
${ }^{5}$ Para uma leitura mais aprofundada desta Reforma, ver capítulos 4 e 5 deste livro.
} 
Esta contrarrevolução "a quente" era necessária não só para a manutenção do poder do Estado nas mãos da burguesia local, mas conforme Lazzarato (2019) era necessária a criação de uma tabula rasa, eliminando qualquer possibilidade de surgimento de um movimento realmente revolucionário capaz de colocar em risco o capitalismo dependente, perseguindo e cassando militantes e contestadores, como no caso do Ato Institucional 05 de 1968, quando diversos professores universitários (dentre eles Florestan Fernandes) foram compulsoriamente aposentados e perseguidos, levando à prisão e exílio destes.

Durante a década de 1960, a educação brasileira viveu uma forte tendência privatista. Após o golpe civil-militar-empresarial, a Reforma Universitária de 1968 buscou atender as necessidades da burguesia, possíveis naquele momento, focalizando na "autonomia" da gestão universitária, no financiamento do ensino superior, na reconfiguração curricular dos cursos e no regime de trabalho dos docentes e servidores técnicos (MINTO, 2014).

Neste momento de contrarrevolução "a quente", foi produzido um relatório sobre a "situação das Universidades Públicas" que ficou conhecido como Relatório Meira Mattos que tinha como objetivo "analisar" e "propor medidas" para "melhor aplicação das diretrizes governamentais, no setor estudantil", deixando claro os interesses da burguesia nacional sobre a universidade pública presentes até hoje, como veremos mais adiante.

No referido relatório constou que seria importante a criação de um "centro acadêmico dedicado com a liberdade e democracia", pois haveria grupos ainda ligados a União Nacional dos Estudantes (UNE) (que foi extinta pelo Decreto-Lei 228 de 1967), grupos de alunos "subversivos e agitadores", sendo necessário a criação de uma entidade representativa "democrática" ligada ao Ministério da Educação e Cultura (MEC).

Havia ainda no relatório a indicação de que o Presidente da República deveria ter o poder de indicar reitores e diretores sem qualquer restrição de lista tríplice ou da necessidade de ouvir o corpo acadêmico e que isto não feriria a autonomia universitária, mas sim reforçaria a "ordem e hierarquia" necessários para o "bom funcionamento de qualquer empresa" (MATTOS, 1968).

É ainda necessário destacar que fora a própria contrarrevolução "a quente" nos países da América Latina que permitiu, através da crise do capitalismo dos anos 1970 e das características fascistóides ${ }^{6}$ destes regimes, que o neoliberalismo pode ser introduzido na região (KLEIN, 2007).

\footnotetext{
${ }^{6}$ Ver capítulo 2 deste livro sobre as características fascistóides dos Estados na América Latina.
} 
Já com a quarta fase do padrão externo de dominação e de transformação da sociedade brasileira estabelecida e com o neoliberalismo introduzido no país através da ditadura civil-militar-empresarial, surge um novo temor da classe burguesa de perda do controle do Estado, frente aos movimentos grevistas que começam a surgir, muitos deles relacionados à educação, o que fez com que a classe dominante aceitasse passar por uma transição "democrática lenta e controlada" a partir de 1985, culminando com a promulgação da Constituição da República Federativa do Brasil em 1988 e as primeiras eleições diretas para presidente, em 1989.

Este movimento entre contrarrevolução "a quente" e "a frio" é perceptível quando analisamos a forma como a burguesia se movimenta na arena política, por meio do controle do Estado, atuando sobre a universidade pública, como analisaremos a seguir.

\section{A CONTRARREVOLUÇÃo BURGUESA “A QUENTE E A FRIO” NA UNIVERSIDADE PÚBLICA DE HOJE}

Os anos pós "transição democrática" em que a contrarrevolução assume sua forma "a frio" que vai de 1985 até 2016 são caracterizados a partir de três aspectos identificados por Lima (2019, p. 19):

(i) estabelecer um pacto de dominação entre as frações da burguesia, em sua dupla face: brasileira e internacional; (ii) construir alianças com a burocracia sindical e partidária da classe trabalhadora; e (iii) limitar as lutas dos trabalhadores à ação constitucional e parlamentar, estimulando o aburguesamento das suas burocracias sindicais e partidárias pela defesa da política de conciliação de classes.

Sob os Governos de Lula da Silva e Dilma Rousseff (2003/2016) estes três aspectos são visíveis desde a cooptação de lideranças de movimentos dos trabalhadores como a Central Única dos Trabalhadores (CUT) para a defesa da reforma da previdência ocorrida no Governo Lula da Silva ${ }^{7}$ e a financeirização das políticas públicas, assim como o aprofundamento e aperfeiçoamento da lógica privatista na Educação Superior (MINTO, 2014) através do Programa Uni-

\footnotetext{
7 "Os funcionários públicos têm que apoiar a reforma da Previdência porque esta é a única maneira de garantir seus benefícios no futuro. A afirmação é do ex-presidente da Central Única dos Trabalhadores (CUT), Jair Meneguelli, hoje presidente do Conselho Nacional do Sesi (Serviço Social da Indústria), um cargo nomeado pelo governo federal.” Entrevista dada ao BBC Brasil, 05 jun. 2003. Disponível em: <https://noticias.uol.com.br/bbc/2003/06/04/ult36u22399.jhtm>. Acesso em: 29 abr. 2020.
} 
versidade para Todos (ProUni) e do Fundo de Financiamento Estudantil (Fies alterado em 2011 permitindo o financiamento de estudantes da educação profissional e tecnológica, através de empresas (LIMA, 2019).

Com a aprovação da Emenda Constitucional n. 95/2016 (BRASIL, 2016), é possível perceber o reaquecimento da contrarrevolução burguesa. Também conhecida como "EC do Teto", esta Emenda Constitucional limita os gastos da União por 20 anos. Houve também a aprovação da contrarreforma trabalhista em 2017 (BRASIL, 2017); e as tentativas de eliminar as conquistas da classe trabalhadora da Constituição Federal de 1988, como a desvinculação de receitas para a saúde e educação.

Estas medidas ameaçam diretamente a manutenção da Educação Superior pelo Estado, assim como afetam a situação do discente, pois com a instituição do "Novo Fies" em 2017, acabando com a carência, obrigando os estudantes a iniciarem o pagamento assim que formados, e permitindo o financiamento por bancos privados, fica marcada a intensificação da ofensiva burguesa sobre os filhos da classe trabalhadora que buscam acesso à educação superior.

É nesta fase "à quente" da contrarrevolução que se reanima, a partir de velhos inimigos como "impedir o comunismo", "evitar novas Cubas", da necessidade de "ajustes fiscais mais profundos", a face reacionária da classe burguesa, que, de fato, nunca deixou de estar presente, pois se trata de um "[...] fascismo oculto e mascarado" (FERNANDES, 2015, p. 52) reacende sua faceta mais autocrática e violenta.

Esta escalada autoritária ${ }^{8}$ transparece e transborda nas ações do Governo Jair Bolsonaro, em especial no fenômeno das Fake News e saídas de ministros acusando o Presidente de agir imoral e ilegalmente. Os episódios das Fake News, dadas as proporções que hoje assumem perante a amplitude de acesso a redes sociais, são uma estratégia antiga de criação de medo e temor na classe burguesa e de incitação à raiva da classe trabalhadora, uma estratégia já verificada quando havia tentativas de manter a contrarrevolução à quente, mesmo du-

\footnotetext{
${ }^{8}$ É necessário esclarecer que quando tratamos do Estado autocrático burguês, não nos referimos apenas as chamadas "ditaduras políticas tradicionais ou, ao os modelos mais elementares de dita dura política, que se realizam mediante o controle absoluto dos meios tradicionais de coação" (FERNANDES, 2020b, p. 427), mas estamos tratando de sistemas de dominação em que preservam-se as funções democráticas, com vistas a manutenção do monopólio do poder econômico, social e política das frações dominantes, passando o Estado a expressar a dualidade intrínseca da ordem legal e política, visando garantir a "democracia" e "liberdade" para uma minoria dominante e o uso da opressão com os dominados, uma forma restrita de democracia (FERNANDES, 2020b).
} 
rante o período da Constituinte, que marcou o início da contrarrevolução "à frio".

Fernandes (1989) identifica que os boatos e mentiras ${ }^{9}$ possuem três objetivos: i) causar medo-pânico na classe burguesa para que essa elite passe a entender a democracia como um "perigo para o país"; ii) unir uma elite burguesa, que passando a enxergar "este perigo", forme uma massa destrutiva e reacionária capaz de aplicar todo seu poder na "defesa da ordem", "custe o que custar"; e iii) estes boatos e mentiras abrem o solo histórico para o golpe de Estado, pois esta burguesia amedrontada e reacionária, capaz de aplicar todo seu poder na "defesa da ordem", recorre ao seu braço militarizado para atacar inimigos (imaginários) internos e externos (FERNANDES, 1989).

Além das Fake News, as saídas de Ministros de forma brusca, como no caso do ex-ministro da Secretaria-Geral Gustavo Bebiano, que deixa o governo afirmando que possuía documentação comprometedora sobre o Presidente Jair Bolsonaro $^{10}$, e a saída do ex-ministro da Justiça e Segurança Pública Sérgio Moro, que fez acusações ao Presidente Jair Bolsonaro de cometimento de crimes de responsabilidade e crimes comuns ${ }^{11}$, são estratégias utilizadas para estabelecer a contrarrevolução "a quente“. Ou seja, conforme Fernandes (1989, p. 162) "[...] os ministros demitidos fazem girar suas metralhadoras a esmo e o Governo retribui, generosamente, desvendando as boas peças que eram (ou são) tais ministros".

No tocante à Educação e especificamente ao que se aplica à universidade pública e à comunidade acadêmica como um todo, o Governo Federal vem retomando medidas e ações do período da ditadura civil-militar-empresarial. Para além das manifestações em redes sociais do Presidente Jair Bolsonaro e do ex-Ministro da Educação Abraham Weintraub, observamos as semelhanças do atual "projeto burguês de educação" com aquele do período da ditadura civilmilitar-empresarial quando comparamos ações, como a nomeação de Reitores de IES desrespeitando a lista tríplice ${ }^{12}$ antes mesmo da edição da Medida Provi-

\footnotetext{
${ }^{9}$ Considerando o período sócio-histórico da Constituinte e do Brasil atual, entendemos haver similaridades entre a estratégia de "mentiras e boatos" com os episódios de "Fake News e mentiras" que ocorrem quase diariamente no Brasil, dadas as diferenças que as formas atuais de mídia e informação permitem.

${ }^{10}$ Disponível em: https://jovempan.com.br/programas/3-em-1/bebianno-diz-que-tem-materialcontra-bolsonaro-nao-tenho-medo-dele.html

${ }^{11}$ Disponível em: https:/g1.globo.com/politica/noticia/2020/04/24/demissao-de-sergio-moroperguntas-e-respostas.ghtml

${ }^{12}$ Disponível em: < https://noticias.uol.com.br/colunas/plinio-fraga/2019/12/26/bolsonarocontrariou-lista-triplice-para-reitor-em-43-das-nomeacoes.htm $>$. Acesso em: 28 set. 2020.
} 
sória n. 914 de 2019, o ID Estudantil ${ }^{13}$ e o programa Future-se ${ }^{14}$.

A nomeação de verdadeiros interventores nas universidades públicas federais e/ou nos Institutos Federais, para além do aspecto de desrespeito à autonomia didático-pedagógica-administrativa das IES prevista no art. 207 da Constituição Federal de 1988 (CRFB/1988), tem o objetivo de intervir e nomear professores alinhados à ideologia do Governo Federal, e isto muito se assemelha a um dos resultados apresentados no Relatório Meira Mattos (1968), como mencionado anteriormente neste capítulo.

Da mesma forma que os interventores nas IES não são mero desejo de autoridade do Presidente Jair Bolsonaro, a criação do ID Estudantil também possuí suas raízes na lógica de controle e perseguição da ditadura civil-militarempresarial do passado recente. No Relatório Meira Mattos foi "constatado" que "[...] não havia uma liderança estudantil democrática" e que, por ser um movimento estudantil tipicamente comandado por "[...] um grupo esquerdista minoritário" (MATTOS, 1968, p. 6) deveria ser criado um Grêmio Estudantil alinhado ao Governo.

Assim, recuperando os elementos de contrarrevolução "a quente" da burguesia no Brasil, o que observamos é que a criação do ID Estudantil, para além de servir como forma de retirar uma fonte de custeio importante da UNE e da União Brasileira dos Estudantes Secundaristas (UBES), sob o argumento utilizado pelo Presidente Jair Bolsonaro de que certos estudantes promovem o socialismo nas universidades, assim como o argumento mais expresso utilizado pelo Ministro da Casa Civil Onyx Lorenzoni de que a UNE e outras instituições são "[...] impregnadas por uma esquerda [...] O que [nós] estamos fazendo hoje é liberar cada jovem"15, razões estas idênticas àquelas apresentadas em 1968,

\footnotetext{
${ }^{13}$ Medida Provisória 895/2019 que perdeu validade em 16/02/2020 por não ter sido analisada pelo Congresso Nacional dentro do prazo constitucional. Esta MP retirava da UNE e Ubes a capacidade de emissão das carteiras estudantis e a passava diretamente para o MEC, possibilitando a criação de um banco de dados com todas as informações de todos os estudantes brasileiros, como foto, biometria, endereço, curso e instituição de ensino que pertence.

${ }^{14}$ O Programa Universidades e Institutos Empreendedores e Inovadores - Future-se passou a tramitar, após três versões apresentadas ao público, na Câmara dos Deputados sob o n ${ }^{\circ} \mathrm{PL}$ 3076/2020. Este programa dividido em três grandes áreas: 1) pesquisa, desenvolvimento tecnológico e inovação; 2) empreendedorismo; e 3) internacionalização. O objetivo do programa é retirar das universidades sua autonomia administrativa, didático-pedagógica e financeira-patrimonial, assim como desconfigurar o tripé ensino-pesquisa-extensão, previstos no artigo 207 da Constituição. Para uma crítica detalhada deste programa ver Giolo; Leher; Sguissardi; 2020.

${ }^{15}$ Disponível em: https://g1.globo.com/educacao/noticia/2019/09/06/bolsonaro-assina-mpque-cria-carteirinha-estudantil-digital-emitida-pelo-governo.ghtml.
} 
abrindo a possibilidade para a criação de um banco de dados com informações como rosto, impressão digital, identidade, $\mathrm{CPF}$, endereço dos estudantes de todo o Brasil. Ou seja, uma forma de controle sobre os estudantes cujo intuito é o mesmo daquele presente no Relatório Meira Mattos, porém, que pode alcançar proporções inimagináveis em razão dos avanços tecnológicos atuais.

Paralelo a isso, o Future-se aprofunda de forma inegável a lógica privatista do período da ditadura civil-militar-empresarial (MINTO, 2014), pois no Relatório Meira Mattos estava posto que era "[...] condição fundamental para o funcionamento de qualquer empresa é a existência de uma estrutura adequada" (MATTOS, 1958, p. 3). Assim, o que temos visto é a tentativa de aprofundamento desta lógica pela introdução do "Programa Universidades e Institutos Empreendedores e Inovadores - Future-se".

O Programa, sob responsabilidade do atual Ministro da Educação Milton Ribeiro ${ }^{16}$ busca não só a continuação do privatismo, mas prevê mudanças estruturais do sistema de Educação Superior, buscando reconfigurar todos os aspectos da Universidade Pública, desde a docência até as escolhas didáticopedagógicas dos cursos. O Future-se possibilita a assinatura de "contratos de resultado" entre Universidades e Institutos Federais e a iniciativa privada, através das fundações de apoio previstas na Lei 8.958 de 1994. Tais contratos podem prever formas de contratação de pessoal docente, desfigurando a carreira do docente federal, precarizando ainda mais a situação destes docentes que já sofrem com constante sobrecarga de trabalho e, atualmente, tiveram seu reajuste conquistado através das Greves Gerais de 2015, suspenso pela PEC 95/2016.

O programa prevê também que as Universidades e Institutos podem transferir para a fundação de apoio a administração de seus imóveis para melhor atender os objetivos do "contrato de resultado", em direta afronta à autonomia administrativa, financeira e patrimonial das Universidades e Institutos prevista no artigo 207 da CRFB/1988.

Além disso, o programa prevê a possibilidade de criação de fundos patrimoniais de investimento utilizando a própria estrutura física das Universidades e Institutos como garantia do investimento privado. Trata-se de transferir o espaço físico da universidade pública para a iniciativa privada e não apenas isto, mas o Future-se prevê a criação de comitês gestores das parcerias firmadas entre Universidades e Institutos e a iniciativa privada, que deteriam o controle da

\footnotetext{
${ }^{16}$ Cabe destacar que o Ministério da Educação já passou pela administração de quatro ministros em um período inferior a 2 anos, sendo que os três ministros anteriores ao atual (Ricardo Vélez, Abraham Weintraub e Paulo Vogel) deixaram o Ministério após casos de incompetência e escândalos.
} 
organização administrativa, patrimonial, financeira e orçamentária destas instituições.

Há ainda, no programa grave ofensa à autonomia didático-pedagógica das Universidades e Institutos, quando nele há a previsão de "promover e disseminar a educação empreendedora por meio da inclusão de conteúdos e atividades de empreendedorismo nas matrizes curriculares dos cursos técnicos, de graduação e pós-graduação".

Evidencia-se, portanto, a forma como a classe burguesa, através do controle do Estado, enxerga e propõe reestruturações da universidade pública e como essas reestruturações constituem uma importante ação da contrarrevolução "a quente" em curso no país.

\section{CONSIDERAÇÕES FINAIS}

Ainda que o capitalismo seja global, as particularidades de cada formação social promoverão traços estruturantes específicos, que na análise realizada sobre a realidade brasileira serão mediados pelo padrão dual de expropriação e espoliação de capital excedente, pelo padrão compósito de hegemonia burguesa e pela revolução burguesa específica das transformações sociais ocorridas no desenvolvimento do capitalismo no país. Vimos que a forma de revolução burguesa brasileira adota, em verdade, uma ação contrarrevolucionária que, em determinados momentos sócio-históricos assumirá a forma "a quente" ou "a frio".

O exame das Fake News e dos ataques à universidade pública por um conjunto de ações conduzidas pelo Governo Federal na atualidade revelam que a contrarrevolução "a quente" segue intensamente. No que se refere a Universidade Pública, o aquecimento da contrarrevolução burguesa busca reestruturar aquele lócus de "[...] comunicação crítica livre, o qual só é possível quando a universidade funciona como uma comunidade de professores e estudantes, originando a fermentação do pensamento inventivo" (FERNANDES, 2011, p. 115).

Cabe à classe trabalhadora agitar-se e promover a verdadeira revolução democrática, centrada nos interesses da classe trabalhadora e não na busca de manutenção da acumulação de riqueza, prestígio e poder da classe burguesa. Assim, defendemos que a classe trabalhadora deve propor seus projetos de sociedade, e no caso específico dos nossos estudos e pesquisas, seu projeto de universidade pública como parte da "revolução dentro da ordem" na ótica dos 
trabalhadores para pavimentação do caminho de construção da revolução contra a ordem burguesa, pois estas revoluções "[...] terão de transcorrer a partir de iniciativas das classes despossuídas e trabalhadoras" (FERNANDES, 2018, p. 13).

Por fim, ressaltamos que o ano do centenário de Florestan Fernandes, pode ser o ano em que a classe trabalhadora, valendo-se de seu talento inventivo revolucionário, assuma a postura de resistência e proposição de projetos que atendam aos seus reais interesses pois, “[...] uma oportunidade real desperdiçada reflete-se numa perda do movimento revolucionário em cadeia (afeta, pois, o presente e o futuro)" (FERNANDES, 2018, p. 31).

\section{REFERÊNCIAS}

BACOCCINA, D. Meneguelli defende apoio da CUT à reforma da Previdência. UOL Últimas Notícias. São Paulo. 04 de março de 2003. Disponível em: $<$ https://noticias.uol.com.br/bbc/2003/06/04/ult36u22399.jhtm $>$. Acesso em: 23 ago. 2020.

BRASIL. [Constituição (1988)]. Constituição da República Federativa do Brasil de 1988. Brasília, DF: Presidência da República [2020]. Disponível em: $<$ http://www.planalto.gov.br/ccivil 03/constituicao/constituicao.htm $>$. Acesso em: 23 ago. 2020.

Emenda Constitucional No 95, de 15 de dezembro de 2016. Altera o Ato das Disposições Constitucionais Transitórias, para instituir o Novo Regime Fiscal, e dá outras providências. Brasília: Congresso Nacional, [2020]. Disponível em: < http://www.planalto.gov.br/ccivil_03/constituicao/emendas/ emc/emc95.htm $>$. Acesso em: 23 ago. 2020.

Lei $\mathbf{n}^{\circ} \mathbf{1 3 . 4 6 7}$, de 13 de julho de 2017. Altera a Consolidação das Leis do Trabalho(CLT), aprovada pelo Decreto-Lei no 5.452, de 1o de maio de 1943, e as Leis nos 6.019, de 3 de janeiro de 1974, 8.036, de 11 demaio de 1990, e 8.212, de 24 de julho de1991, a fim de adequar a legislação às novasrelações de trabalho. Brasília, DF: Presidência da República, [2020]. Disponível em: < http://www.planalto.gov.br/ccivil 03/ ato2015-2018/2017/lei/L13467.htm>. Acesso em: 23 ago. 2020. 
FERNANDES, F. A constituição inacabada: vias históricas e significado político. São Paulo: Estação Liberdade, 1989.

Sociedade de classes e subdesenvolvimento. 5. ed. rev. São Paulo: Global, 2008.

Capitalismo dependente e classes sociais na américa latina. 4. ed. rev. São Paulo: Global, 2009.

Brasil: Em compasso de espera: Pequenos escritos políticos. Rio de Janeiro: Editora UFRJ, 2011.

Poder e contrapoder na América Latina. São Paulo: Expressão Popular, 2015.

. O que é revolução. São Paulo: Expressão Popular, 2018.

. Universidade brasileira: Reforma ou revolução? São Paulo: Expressão Popular, 2020a.

A Revolução burguesa no Brasil: Ensaio de interpretação sociológica. 6. ed. São Paulo: Editora Contracorrente, 2020b.

FRAGA, P. Bolsonaro contrariou lista tríplice para reitor em 43\% das nomeações. UOL Notícias. São Paulo. 26 de dezembro de 2019. Disponível em: < https://noticias.uol.com.br/colunas/plinio-fraga/2019/12/26/bolsonaro-contrariou-lista-triplice-para-reitor-em-43-das-nomeacoes.htm $>$. Acesso em: 23 ago. 2020.

GIOLO, J.; LEHER, R.; SGUISSARDI, V.; Future-se: Ataque à autonomia das instituições federais de educação superior e sua sujeição ao mercado. São Paulo: Diagrama Editorial, 2020.

G1. Demissão de Sergio Moro: perguntas e respostas. G1. São Paulo. 24 de abril de 2020. Disponível em: < https://g1.globo.com/politica/noticia/ 2020/04/24/demissao-de-sergio-moro-perguntas-e-respostas.ghtml>. Acesso em: 30 ago. 2020. 
KLEIN, N. The shock doctrine: the rise of disaster capitalism. New York: Picard, 2007.

LAZZARATO, M. Fascismo ou revolução? O neoliberalismo em chave estratégica. São Paulo: N-1, 2019.

LIMA, K. Universidade pública e contrarrevolução: da "travessia de uma ponte" ao "caminho da prosperidade". Revista Em pauta, Rio de Janeiro, v. 17, n. 44, p. 15-32, ago./dez. 2019.

MATTOS, C. de M. Relatório Meira Mattos. Correio da Manhã. Rio de Janeiro, Ano 1968, ed. 23122, p. 1. 25 de agosto de 1968. Disponível em: < http://memoria.bn.br/DocReader/Hotpage/HotpageBN.aspx? bib=089842 07\&pagfis $=94 \% 20970 \& u r l=h t t p: / /$ memoria.bn.br $/$ docreader\# $>$. Acesso em: 23 ago. 2020.

MAZZEO, A. C. Estado e burguesia no Brasil: origens da autocracia burguesa. São Paulo: Boitempo, 2015.

MINTO, L. W. A educação da miséria: particularidade capitalista da educação superior no Brasil. São Paulo: Outras Expressões, 2014.

NETTO, J. P. Relendo a teoria marxista da história. In: SAVIANI, D. et al. (org.). História e história da educação. O debate teórico-metodológico atual. São Paulo: Autores Associados, 2018.

OLIVEIRA, F. Crítica a razão dualista: ornitorrinco. 1. ed. 4. reimp. São Paulo: Boitempo, 2013.

PAN, J. Bebianno diz que tem material contra Bolsonaro: 'Não tenho medo dele'. Jovempan. São Paulo. 20 de dezembro de 2019. Disponível em: $<$ https://jovempan.com.br/programas/3-em-1/bebianno-diz-que-tem-material-contra-bolsonaro-nao-tenho-medo-dele.html>. Acesso em: 23 ago. 2020.

RODRIGUES, M. Bolsonaro assina MP que cria carteirinha estudantil digital, emitida pelo governo. G1. São Paulo, 06 de setembro de 2019. Disponível em: 
<https:/g1.globo.com/educacao/noticia/2019/09/06/bolsonaro-assina-mpque-cria-carteirinha-estudantil-digital-emitida-pelo-governo.ghtml > . Acesso em: 23 ago. 2020.

TROTSKY, L. A revolução permanente. 2. ed. São Paulo: Expressão Popular, 2007. 